\title{
Peer support for undergraduate children's nursing students
}

\author{
Fiona Cust, Keeley Guest \\ Children's Nursing, School of Health and Social Care, Staffordshire University, UK
}

Received: October 9, 2019

Accepted: December 13, 2019 Online Published: December 20, 2019

DOI: $10.5430 /$ jnep.v10n4p21

URL: https://doi.org/10.5430/jnep.v10n4p21

\begin{abstract}
Background and objective: The provision of appropriate 'pastoral' support for nursing students is acknowledged to be problematic for a variety of reasons, (time constraints, staffing levels, unmanageable workloads). The need to initiate and access more suitable support is imperative - particularly in the light of the increasing number of students suffering with mental health issues. This study examines the dynamics of a student peer support programme over a two-year period. Twenty-one first year students (child field) gave fully informed consent to being involved in a peer support study. Nineteen second year students (again, child field) consented to being peer supporters for the junior students.

Methods: The team, consisting of two academics and two clinicians, explored the relatively simple option of second year nursing students 'peer supporting' first year students in various aspects of their training over a two-year period - from social support, academic support, pastoral support and clinical support. An evaluation of the initiative was through a questionnaire at four separate intervals over the two-year period.

Results: The results were hugely positive, and encouraging. Both cohorts of student found the intervention accessible, supportive, and sustainable. Peer support may be a relatively straightforward, and simple concept to assist junior nursing students in their often very complex, and overwhelming, transition.
\end{abstract}

Key Words: Peer support, Nursing student, Mental health

\section{INTRODUCTION}

In the ever changing and increasingly demanding environment of undergraduate nursing students' education, the decline of student mental ill-health is becoming a national, if not global, issue.

The development and availability of higher education in the UK has resulted in an increasingly diverse student population particularly over the past two decades. This is a hugely positive and very welcome fact, but alongside comes a number of challenges. The Equality Act (2010) provides a legal framework to protect the rights of individuals and advance equality of opportunity for all. This therefore places a legal duty on higher education institutions (HEI's) to ensure that students, with protected characteristics, have equality of opportunity. Mental ill-health can impact dramatically on not only students' wellbeing but also upon their academic attainment. If HEI's fail to provide support for students with mental health issues there is an increased risk that the student will withdraw from their programme, achieve lower academic and employment outcomes and, crucially, become increasingly unwell.

This applies to all students but perhaps even more so to un-

\footnotetext{
*Correspondence: Fiona Cust; Email: Fiona.Cust@staffs.ac.uk; Address: Children’s Nursing, School of Health and Social Care, Staffordshire University, UK. 
dergraduate nursing students. They are not only juggling the multidimensional transition of university but, in addition, are also coping with the ever-increasing demands of hospital and community placements.

Peer support is not a new concept and indeed, peer support is used nationally and globally. However, it does not appear to be utilised, routinely, or even at all, within undergraduate nursing programmes. Programmes of peer support can include one to one, group and online support. The evidence on the effectiveness of peer support is largely inconclusive, ${ }^{[1]}$ and suggests that there may be several key characteristics of effective peer support programmes - specifically for those with a focus upon mental health and well-being. Characteristics include commitment, empathy, time, support for the peer supporter, and a shared experience. It has been suggested that effective peer support can have a positive effect on both supporter and receiver. ${ }^{[2]}$ The primary aim of this study was to ascertain the effectiveness of peer support between a new student beginning their transition to university, and a senior student in their transition to qualified nurse status.

\section{METHOD}

Twenty-one first year students (child field) gave fully informed consent to being involved in the peer support study. Nineteen second year students (again, child field) consented to being peer supporters for the junior students.

A 'meet and greet' informal lunchtime was held within the student social space and each student met their peer supporter. The students had been allocated randomly as it would be rather difficult to 'pair' them appropriately due to the junior students being new undergraduates and little known about their personalities. The academic team provided an informal setting, lunch, and introduction, but then retreated to encourage a more relaxed approach. The students provided feedback after the lunch and each individual group appeared very positive about the intervention.

Numbers/emails/snap chats had been exchanged and a discussion about a social media forum for all participants was also agreed and formatted the following day.

Within the context of health professional education, peer learning/mentoring approaches have been used to assist students within the clinical area - in the progression of their skills. ${ }^{[3]}$ This was not the purpose for this intervention although they may share concerns or anxieties associated with the clinical area, the primary focus was a more general supportive approach towards their transition to University life within a healthcare profession.

\subsection{Data analysis}

A questionnaire was forwarded to each group at a six-month period after the peer support program had commenced, and again after a year. This was then repeated again after eighteen months and, finally after two years (when the peer supporters graduated and the first-year students entered into their final year).

Sixteen junior students completed all questionnaires, and fourteen senior students completed all questionnaires. This was an excellent response rate from both cohorts.

The questionnaires were in a very general format to ascertain if peer support had been accessed, how regularly and the outcome (both positives and negatives). The data was anonymised to, ideally, encourage the students to be open and to share their experiences in confidence. To analyse the data, a constant comparative method was used. ${ }^{[4]}$ The lead researcher read the text data, compared new codes and categories as they emerged, and then revisited the data again to ensure that they had interpreted correctly, and that the emerging themes were appropriate. Similarities and differences were highlighted; categories and codes were subsequently collated. The feedback was analysed separately and the initial themes were from the earlier questionnaires, the remaining themes were from the later questionnaires. What was very apparent was the continued need for support but in very different ways and for many different reasons.

\section{RESUlts}

Prior to the intervention starting, the undergraduate nursing students were asked, informally, what they felt may be beneficial towards helping to promote their self-esteem and improve their experience at university. A number of suggestions were raised including, 'someone to relate to, to talk to without feeling intimated', 'someone like minded who may understand where I am coming from', 'that wouldn't make me feel stupid because I don't really know anything!'

The second-year undergraduate nursing students (the peer supporters) were also asked about their perceived perception of what the intervention may help with. Responses were largely positive and raised comments that we were not necessarily expecting, 'I think that it would not only help the first years' but may boost my confidence too,' 'this would be such great preparation for the transition to my second year', 'happy to share any tips and helpful suggestions, I could have done with this when I first started too'. Other students were a little less enthusiastic but primarily as they were concerned about prioritising their own work and progression in training - 'Just a bit worried that I may not have the headspace right now to give as much to this that I would like to,' 'Think it 
is such a good idea but my head bursting with being in my second year at the moment. I may not be a great example!'

As requested by the students, a formal counselling role was neither discussed or adopted. The senior students wanted to 'find their own way of helping', 'offer support', 'helpful suggestions' and 'provide a shoulder to lean on or cry on, or both!' A number of the second years were keen to 'make the journey a little less traumatic or scary' for the new students. They requested the academic staff had 'minimal input' as it may therefore encourage the junior students to feel 'more at ease and relaxed' if seeking support and guidance. Support, and either group or one to one supervision would be regularly available and actively encouraged for any student, (either receiving support or providing support), and this was reinforced prior to the intervention commencing.

It was apparent that the junior students had a several similar anxieties that they shared with the more senior students, these have been categorised into the following themes, 'expectations of others', 'out of my depth', 'frightened of making a mistake', 'lonely' and 'too many new experiences at once'.

A number of the junior students were unsure about expectations of others and, indeed, what to really expect. They felt that the more senior students were 'a haven to ask questions that may sound unbelievably silly', 'they had been there, seen it and done it, so could really tell me what to expect', 'information that perhaps I ought to know, and didn't, I felt ok to ask another student - but not ask a tutor as they may think that I am stupid.'

They also seemed to share anxieties about seemingly, being seen as 'incompetent'. 'I think well, I really should know the facts but actually I don't, so I will just give my peer supporter a call or an email as I know he will not judge me' 'It's perhaps simple stuff that are really insignificant but would be great to know - so I just ask my peer as they seem to know what to say or what to do.' 'I've haven't ever even set foot into a skills area before and felt as if I was stepping into an abyss. What if I broke something or worse still, I passed out!! I text my peer to find out what it was all about and she was really great, made me laugh, and totally put my mind at rest.'

The overriding feeling of loneliness was repeatedly raised during the analysis. A number of the students had moved away from home for the first time and this was making some of them feel 'isolated' and very 'homesick'. They felt that they were 'coping with far too much all at once' and, although I am sure this is relevant to other degree programmes too; the students were displaying heightened anxiety regarding learning new clinical skills and the challenge of clinical placements.

Their peer supporters certainly helped with this aspect. It would appear that several of them would arrange to meet up and go out as a group. The senior students provided useful information about where to go, cost and transport and this was deemed to be very useful.

'If I felt low and homesick, I would message my peer and she would say, oh I felt exactly the same but it gets easier over time. Why not face time me and we can have a chat?'

There were a number of anxieties focussed around their academic work too but, again, their feedback about the suggestions and input from their peer were most encouraging and logical!

'It is so reassuring to know that others have had to resubmit an assignment too, or redo an exam, it doesn't mean that I am stupid or that I won't be able to complete my degree, just that I need to get some more help.' 'I felt such an idiot, felt that I was never ever going to complete my training but my peer supporter had been there too, she had to resubmit two assignments and has still managed to survive, it was such a relief.' 'Although my module tutor is great and is really encouraging there are some things that I feel silly asking her, it was great to be able to contact my peer as I felt that they wouldn't judge me or think that I was being really silly!'

Interestingly, two of the junior students did express concerns about the possibility of not completing their training if it had not been for the input from their peer supporter - raising the question as to whether a robust peer support system may have a positive impact upon student attrition.

The peer supporters found the initiative a positive experience too. They talked about 'a sense of belonging, an importance' and a 'moral and boost to their confidence'. Several of the students described feeling 'empowered' and, in fact, felt that it was a good grounding for them prior to their transition to qualified nurse status. 'It made me think that I had actually achieved something, I'd learnt something and maybe I would be ok as a Staff Nurse, it really helped.' 'I wish that I had had this opportunity when I was a first year, it would have helped greatly. I really think that it would have made a difference to my first year.' 'My student asked me lots of things that I know that I had always wanted to ask someone - anyone really - when I first started my degree.' 'It was like a light bulb moment - I do know stuff! But I also still have lots to learn - but at least I have learnt some things! This was a really positive thing as I could acknowledge what I knew but also acknowledge what I still really needed to know.'

The later questionnaires and indeed the final questionnaires 
were more reflective in their accounts. A number of themes emerged from the final comparative of data - 'a lifesaver', ' $a$ confidante', 'one of the reasons that I am still on my degree programme', 'a confidence booster', 'a positive light'.

Many of the students were very emotive in their final reflections. It was rather daunting to read comments such as ' $I$ would not still be here if it had not been for my peer supporter', 'at the end of a horrible shift when you are literally worn down with it all my peer would drop me a quick text with some encouraging words and I would feel so much better', 'it helped to know that others feel the same, they have rubbish days too when they are full of self-doubt, it is good to know that you aren't the only one struggling.' 'Sometimes mentors can be a little harsh, a bit too reactive, say things that you take probably completely the wrong way. My peer had had the same mentor and could relate to this - it made me feel so much better knowing it wasn't personal.'

The senior students did access support occasionally from the allocated member of the research team - particularly if they were very worried about their junior student. Guidance and support were readily offered and, indeed, three of the junior students were signposted for further mental health provision with one being referred to a specified therapist. This was viewed as a further positive from the peer support study as this may have ended very differently without the senior student raising their concerns.

The senior students also appeared to benefit from their role as peer supporters - and this developed greatly over the twoyear period. Feedback included 'my confidence has grown greatly by undertaking this role, I wasn't aware that I knew half of the stuff that I actually do, I feel quite good about myself.' 'I really want to mentor students in practice when I qualify, it is a role that is so beneficial and makes such a positive difference'. 'Feel that I have really achieved something worthwhile, I mean I know I have by completing my training but this feels so good, like I have really helped someone.'

\section{Discussion}

Peer assisted learning has been described by Christiansen et al. (2010) $)^{[5]}$ as the term used to describe a group of ideas which include cooperative learning, collaboration and peer coaching. It has been suggested that benefits can be accrued to all students - the junior students build their confidence through their peer and the senior students gain a deeper understanding of their role - and this, in turn, may assist in both a development of their own learning and development, enhancement of communication skills, and finally, transition to qualified practitioner. ${ }^{[6]}$

The peer support programme provided additional support, in a collegial manner, to the first-year undergraduate nursing students - whilst simultaneously developing the senior student's confidence.

An interactive learning board was created by the peer supporters for all students (both junior and senior). The students' added a 'frequently asked questions' section- and responses - and this was added to and amended on a weekly basis as more and more questions were asked. The board was utilised constantly and appeared to be a very useful resource for both the students within the study, and for other students within the School.

In addition, the peer supporters provided constructive feedback to academics within the school about a variety of different aspects - for example, teaching styles, extra curriculum activities, and inconsistencies about information/skills being imparted/taught. They provided an invaluable link between students and academic staff - this, in turn, helped to 'close gaps' between the students and the teaching staff.

The peer supporters were able to provide one to one support to new students about many different issues. Questions were asked and reassurances were sought about assignments, classrooms, finances, policies and procedures, transport, social events, and clinical placements. With the ever-increasing demands upon academic staff, this is a valuable student focussed service that appeared to have a positive impact upon the time constraints placed upon teaching staff.

There are considerable opportunities for the further development of this initiative informed by the students' experiences. A suggestion was made to collate a profile of the senior students so that the junior students could have the option to 'select' their peer supporter. Time pressures, as acknowledged by earlier studies, ${ }^{[7,8]}$ did impact upon face to face meetings. Students suggested regular, structured timetable meetings to be incorporated into the curriculum to ensure that there are opportunities to meet. Gilmour et al. (2007) ${ }^{[7]}$ have noted the importance of the person being supported having realistic expectations of their peer. This study did reiterate the importance of preparing, and supporting, both the peer supporters and the students receiving their input.

\section{Conclusion}

In light of the many benefits to both the junior student and the senior student, increasing numbers of students need to be provided with this experience of peer support. This role may improve leadership, self-esteem, knowledge, networking and confidence. And, most importantly, may have a positive impact upon student mental health. Participants reported feeling 'welcome, a sense of belonging, inspired, challenged, rewarded, confident, secure and generally happier.' This 
may also have a positive impact upon the time limitations placed upon academic staff too. A more joined-up approach between the academic, clinical, and social elements of the university is required and is essential. A wider understanding and, indeed, acknowledgement, of the pressures nursing students (and other students) face is vital if we are to ensure that the provision for mental health issues meets, or even attempts to meet, their ever-increasing needs.

The evaluation of findings did indicate that peer support programmes do require structure and commitment and that both groups of students require preperation both to manage their role and their expectations. This has now been incorporated into the intervention, in addition to timetabled sessions being an integral part of the undergraduate curriculum within the university.

This has become a rolling programme in the children's undergraduate nursing degree within the University and has also commenced within the mental health undergraduate degree program.

Further studies are required to explore the potential that this may have upon student mental health and student retention.

\section{CONFLICTS OF INTEREST Disclosure}

The author declares that there is no conflict of interest.

\section{REFERENCES}

[1] Weare K, Nind M. Mental health promotion and problem prevention in schools: what does the evidence say? Health Promotion International. 2011 Dec; 26: 29-69. PMid:22079935 https: //doi.org/10.1093/heapro/dar075

[2] Cust F. Increasing confidence of first-year student nurses with peer mentoring. Nursing Times [online]. 2018; 114(10): 51-53.

[3] Sprengel A, Job L. Reducing Student Anxiety by Using Peer Mentoring with Beginning Nursing Students. Nurse Educator. 2004; 29(6): 246-250. PMid:15586121 https://doi .org/10.1097/00 006223-200411000-00010

[4] Denscombe M. The Good Research Guide 5th Edition. Open University Press; 2016.
[5] Christiansen A, Bell A. Peer Learning Partnerships: Exploring the Experience of Pre-Registration Students. Journal of Clinical Nursing 2010; 19(5-6): 803-810. PMid:20500324 https ://doi .org/10.1 $111 / j .1365-2702.2009 .02981 . x$

[6] Dennison S. Peer Mentoring - Untapped Potential. Journal of Nurse Education. 2010; 49(6): 340-342. PMid:20210287 https://doi . org/10.3928/01484834-20100217-04

[7] Gilmour A, Kopelin A, Douche J. Student nurses as peer mentors: Collegiality in practice. Nurse Education in Practice. 2007; 7: 36-43. PMid:17689422 https://doi.org/10.1016/j.nepr.2006.04 .004

[8] Eby LT, Lockwood A. Proteges and mentors' reactions to participating in a formal mentoring program: a qualitative investigation. Journal of Vocational Behaviour. 2005; 67(3): 441-458. https://doi.org/10.1016/j.jvb.2004.08.002 